\title{
Evaluation of 99mTc-Ethambutol Radiopharmaceutical Using High Performance Liquid Chromatography with Radioactive Detector (Radio-HPLC)
}

\author{
Maula Eka Sriyani*, Rizky Juwita Sugiharti, Eva Maria Widyasari, Iim Halimah \\ Center for Applied Nuclear Science and Technology National Nuclear Energy Agency JL. \\ Tamansari No. 71 Bandung 40132, Indonesia
}

\author{
Submitted 4 March 2019; Revised 16 April 2018; Accepted 23 April 2019; Published 13 May 2019 \\ *Corresponding author: maula@batan.go.id
}

\begin{abstract}
${ }^{99 \mathrm{~m}}$ Tc-ethambutol is a radiopharmaceuticals used to determine the location of Mycobacterium tuberculosis that causes TB disease. To prepare this radiopharmaceuticals, supporting compounds such as mannitol as filler, $\mathrm{SnCl}_{2}$ as a reducing agent and sodium pyrophosphate as co-ligand are required in addition to ethambutol and radionuclide compounds. The radiopharmaceuticals is made in the form of a lyophilized kit without ${ }^{99 \mathrm{~m}} \mathrm{Tc}$ radionuclides. The aim of this study was to determine the effect of reducing agents on ${ }^{99 \mathrm{~m}} \mathrm{Tc}$-ethambutol preparation using the High Performance liquid chromatography (HPLC) equiped with radiodetector (radio-HPLC) to the quality of radiopharmaceuticals. In the previous study, the determination of radiochemical purity only used TLC by determining the amount of impurities $\mathrm{TcO}_{2}$ and $\mathrm{TcO}_{4}$ - This study was carried out more profoundly by using radio-HPLC to ensure the quality of radiopharmaceutical products. The test were performed using paper chromatography, electrophoresis, radio-HPLC, and stability test of ${ }^{99 \mathrm{~m} T c-e t h a m b u t o l ~ r a d i o p h a r m a c e u t i c a l s . ~ T h e ~ r e s u l t s ~}$ showed that the radiopharmaceutical kit of ethambutol is performing good physical characterictics and high radiochemical purity of ${ }^{99 \mathrm{~m}} \mathrm{Tc}$-ethambutol in analysis using radio-HPLC as well as paper chromatography and electrophoresis. The retention time $\left(\mathrm{t}_{\mathrm{r}}\right)$ of ${ }^{99 \mathrm{~m}} \mathrm{Tc}$-ethambutol were found at 7.97 minutes using UV and radioactive detector, C18 column, isocratic system using phosphate buffer $0.2 \mathrm{M}$ pH 7.4 and Acetonitrile $(90: 10)$, flow rate $0.8 \mathrm{~mL} / \mathrm{min}$. The radiochemical purity of ${ }^{99 \mathrm{~m} T c-e t h a m b u t o l}$ is still remain high $(91.44 \pm 0.92 \%)$ after 27 days of kit were made. From the results, it was concluded that radio-HPLC analysis provides better information on radiochemical purity as well as chemical purity of the labeling of ${ }^{99 m} \mathrm{Tc}$-ethambutol.
\end{abstract}

Keywords: ${ }^{99 m}$ Tc-ethambutol, Radio-HPLC, TB disease, Mycobacterium tuberculosis, Radiopharmaceuticals.

\section{Introduction}

The performance of a radiopharmaceutical kit is determined not only by radiochemical/chemical purity but also by physical appearance. Stability testing is termed as a complex process because several factors that influencing the stability of a pharmaceutical product ${ }^{1}$. A pharmaceutical product may undergo change in appearance, consistency, content uniformity, clarity (solution), moisture contents, particle size and shape, $\mathrm{pH}$, package integrity thereby affecting its stability. Such physical changes may be caused by impact, vibration, abrasion, and temperature fluctuations such as freezing, thawing or shearing. The chemical reactions like solvolysis, oxidation, reduction, racemization that occur in the pharmaceutical products may lead to the formation of degradation product, loss of potency of active pharmaceutical ingredient (API), loss of excipient activity like antimicrobial 
preservative action and antioxidants ${ }^{2}$. The radiopharmaceutical stability is defined as the time during which the radioisotope can be safely used for the intended purpose. The radiochemical stability studies must be conducted to represent the effective use of the product ${ }^{3}$. The physical-chemical characteristics of a radiopharmaceutical determine its pharmacokinetics, i.e., its fixation on the target organ, metabolism and excretion of the organism, whereas the physical characteristics of the radionuclide determine the application of the compound in diagnosis or therapy ${ }^{3}$.

High Performance Liquid Chromatography (HPLC) is a popular analytical technique used for the separation, identification and quantification of each constituent of mixture ${ }^{4}$. In this research, the HPLC uses two different detectors, the $\mathrm{UV}-\mathrm{V}$ is detector and radioactivity detector, hence it called radio-HPLC. The UV-visible absorbance detector is the most common HPLC detector in use today since many compounds of interest absorb in the UV (or visible) region (from 190-600 $\mathrm{nm}$ ). Radioactivity detectors (sometimes referred to as radiometric or radio-flow detectors) are used to measure radioactive analytes as they elute from the HPLC column ${ }^{4}$. Most of the HPLC systems currently available are controlled via a suitable software, which is also used to acquire and process signals coming from detectors ${ }^{5}$. The radioactivity detector can be very sensitive and is extremely useful for the detection of radiolabeled compounds in toxicological, metabolism, or degradation studies ${ }^{6}$. Analysis of radiochemical purity using HPLC is recommended in order to quantify the radiochemical purity of the preparation before its administration to patients ${ }^{7}$.

Previous research that using HPLC as a modality for determination of labeled compound was conducted by Mihon, et al. for detection of $\mathrm{Na}^{18} \mathrm{~F}^{8},{ }^{68} \mathrm{Ga}$-labeled protein by Irina Velikyan ${ }^{9}$, Tian-Ze Zhou conducted determination of ${ }^{99 \mathrm{~m}} \mathrm{Tc}$-pertechnetate using HPLC ${ }^{10}$ and also Van Hemert et.al using HPLC to quantify the quality of ${ }^{99 m} \mathrm{Tc}-$ mertiatide (Mag-3) ${ }^{7}$.

This study was conducted to evaluate the quality of the radiopharmaceutical kit of ethambutol made in packs of two vials (reducing agents and ligands) using paper chromatography/TLC, electrophoresis and radio-HPLC to determine radiochemical purity as well as chemical purity and also determine the stability of the radiopharmaceutical kit.

\section{Materials and methods}

\subsection{Materials}

Ethambutol-HCl, Na-pyrophosphate (Sigma-Aldrich), $\quad \mathrm{SnCl}_{2} \cdot 2 \mathrm{H}_{2} \mathrm{O}$ (Wako), $\mathrm{Na}^{99 \mathrm{~m}} \mathrm{TcO}_{4}$ (Polatom), Acetone (Merck), Acetonitrile (Merck), phosphate buffer pH 7.4 0.2M,Aquabidest(IPHA),ITLC-SG(Agilent), Whatman 31ET, Whatman 1, cellulose acetate paper, $\mathrm{pH}$ indicator universal (Merck), metal free vials, syringe (Terumo), analytical balance (Mettler Toledo), vortex stirrer (lab companion), micropipette (Eppendorf), tip, oven (Heraeus), Chromatography chamber, paper electrophoresis set (Mojor science), microtube, lead container, HPLC equipped with GABY-star detector (Agilent), Single Channel Analyzer (SCA) (Ortec), Dose Calibrator (Victoreen) and TLC scanner (Bioscan AR-2000).

\subsection{Methods}

\subsubsection{Labeling of ${ }^{99 \mathrm{~m}} \mathrm{Tc}$-ethambutol}

A total of $3.5 \mathrm{mg}$ of Na-pyrophosphate was dissolved in $1 \mathrm{~mL}$ of aquabides, then $1.4 \mathrm{mg}$ of $\mathrm{SnCl}_{2} \cdot 2 \mathrm{H}_{2} \mathrm{O}$ was added (Vial A). In another vial (Vial B), $3.5 \mathrm{mg}$ ethambutol and $5 \mathrm{mg}$ Manitol were dissolved in $0.5 \mathrm{~mL}$ aquabidest. In to vial $\mathrm{B}$ was added $0.5 \mathrm{~mL}$ of solution in vial $\mathrm{A}$ and $1 \mathrm{~mL}$ of $\mathrm{Na}^{99 \mathrm{~m}} \mathrm{TcO}_{4}$ (2-5 $\mathrm{mCi})$. The radiochemical purity testing was carried out by using two chromatographic systems, first eluent is acetonitrile $50 \%$ and whatman $31 \mathrm{ET}$ as a stationary phase and the second is dry acetone as an eluent and ITLCSG as stationery phase.

\subsubsection{Electrical charge determination of ${ }^{99 \mathrm{~m}} \mathrm{Tc}$ - ethambutol Using paper electrophoresis Determination of electrical charge was done through cellulose acetate paper}


electrophoresis method. Cellulose acetate paper was immersed in a phosphate buffer $\mathrm{pH} 7.40 .2 \mathrm{M}$ for 30 minutes and dried by tapping it with tissue paper. Then cellulose acetate paper is placed in an electrophoresis device. The cellulose acetate paper was added by $2 \mu \mathrm{L}{ }^{99 m} \mathrm{Tc}$-ethambutol at zero point, then electrophoresed for 1 hour with a 5A current/ paper and a potential of $200 \mathrm{~V}$.

\subsubsection{Analysis of impurity using radio-HPLC}

The purity of ${ }^{99 \mathrm{~m} T c-e t h a m b u t o l}$ were done by the reverse phase method using $\mathrm{C} 18$ column. The elution system is isocratic and the mobile phase is mixture of phosphate buffer $0.2 \mathrm{M} \mathrm{pH} 7.4$ and Acetonitrile (90:10). The flow rate $0.8 \mathrm{~mL} / \mathrm{minute}$ for retention time of 30 minutes. The detectors used were GABI star for radioactive and UV with wavelength of $202 \mathrm{~nm}$

\subsubsection{Stability determination of ${ }^{99 \mathrm{~m}} \mathrm{Tc}-$ Ethambutol \\ Chemical stability of a drug is the} length of time for a drug to maintain the chemical integrity and its potential as stated in the label within the prescribed time limit. Physical stability is evaluating changes in the physical properties of a product depending on the time (storage period). The examples of physical changes include the change in color, taste, smell, texture or appearance. Evaluations of physical stability tests include organoleptic examination, homogeneity, $\mathrm{pH}$ and specific gravity. Stability testing is carried out by determining the radiochemical purity of ${ }^{99 m}$ Tc-ethambutol over a certain time period. In addition to radiochemical purity, stability testing is also carried out on the physical conditions of the preparation and the kits obtained. The test was carried out at 0-6 hours after labeled with technetium-99m and for 30 days using paper chromatography.

\section{Results}

The result in table 1 . descibed the physical and chemical performance of radiopharmaceutical kit of ethambutol. From the result, it is shown that both the radiochemical purity of ${ }^{99 \mathrm{~m} T c-e t h a m b u t o l}$ and its impurities also the $\mathrm{pH}$ were met the requirements as a good radiopharmaceutical.

${ }^{99 m}$ Tc-ethambutol radiopharmaceuticals consisted of several ingredients which are ethambutol, pyrophosphate, and also mannitol. The conventional tests to determine the radiochemical purity of ${ }^{99 \mathrm{~m}} \mathrm{Tc}$-ethambutol is using paper chromatography. The paper/ TLC chromatography method cannot separate the ${ }^{99 m}$ Tc-pyrophosphate impurities which may be formed during the labeling process. Therefore the radio-HPLC were used to determine radiochemical purity as well as chemical impurities.

The electrophoresis method were done to assign the electrical charge of the ${ }^{99 \mathrm{~m}} \mathrm{Tc}-$ ethambutol, from the result from figure 1., it has shown that ${ }^{99 m}$ Tc-ethambutol has a negative charge and it was correspond to previous result ${ }^{11}$.

Table 1. Performance of radiopharmaceutical kit of ethambutol

\begin{tabular}{|c|c|}
\hline Parameter & $\underline{\text { Result }}$ \\
\hline Radiochemical purity & $92.61 \% \quad \pm \quad 4.59 \%$ \\
\hline $\mathrm{TcO}_{2}$ & $1.55 \% \quad \pm \quad 0.97 \%$ \\
\hline $\mathrm{TcO}_{4}^{-}$ & $5.83 \% \quad \pm \quad 4.47 \%$ \\
\hline $\mathrm{pH}$ & $8,5-9$ \\
\hline Physical appearence & 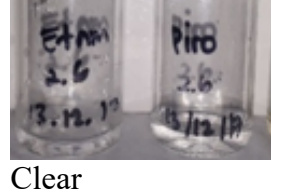 \\
\hline
\end{tabular}




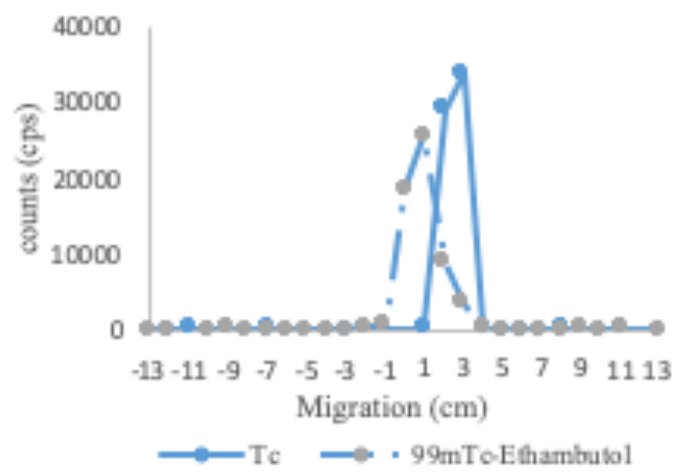

Figure 1. Celulose acetate paper electrophoresis chromatogram of ${ }^{99 \mathrm{~m}} \mathrm{Tc}$-ethambutol
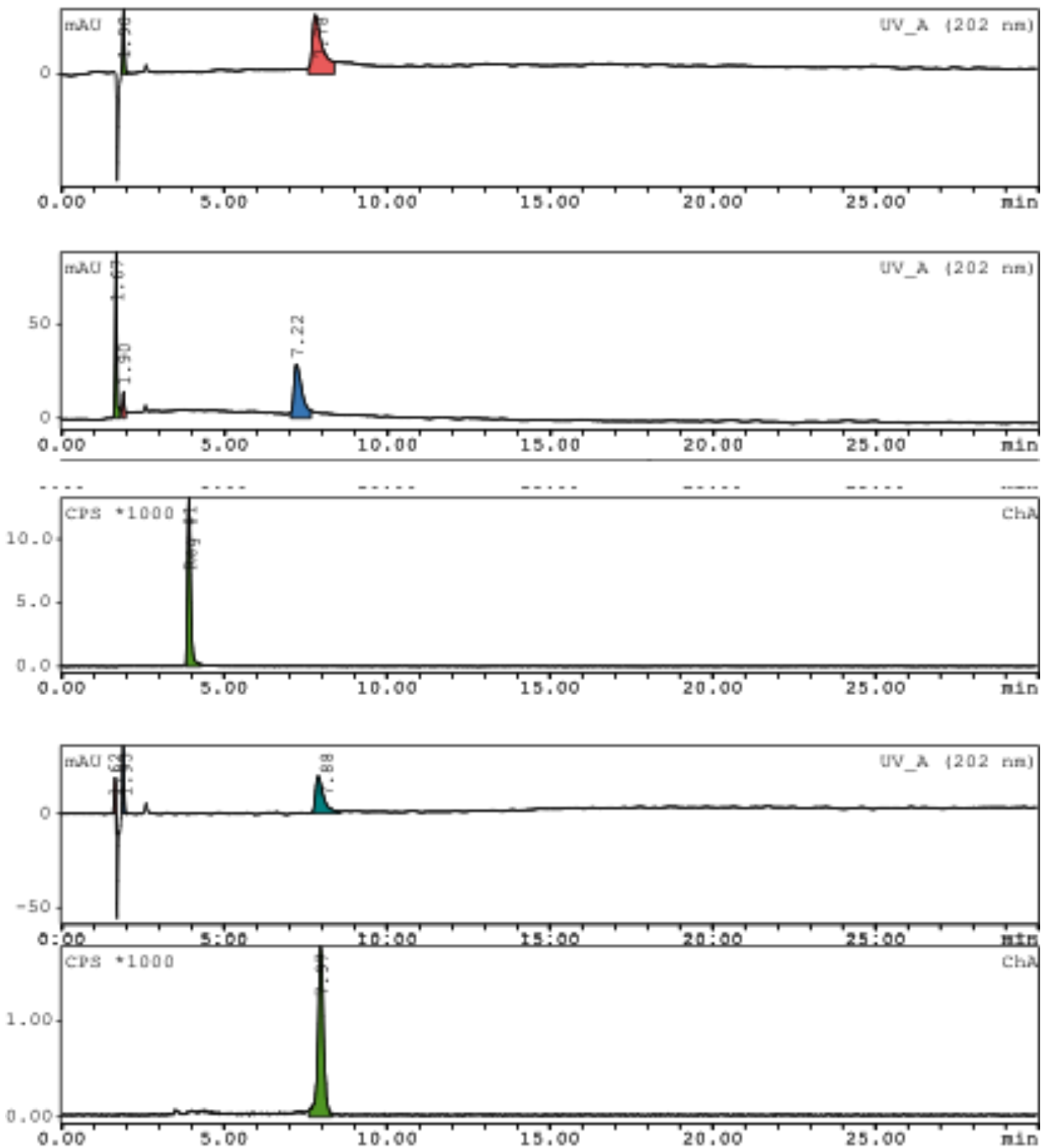

Figure 2. High Performance Liquid Chromatography (HPLC) pattern of (a) ethambutol, (b) mixture of $\mathrm{Sn}$, pyrophosphate and ethambutol (c) $\mathrm{TcO}_{4}^{-}$and (d) ${ }^{99 \mathrm{~m}} \mathrm{Tc}$-ethambutol

The result from HPLC detection of $7^{\prime}$, while the cold kit (without ${ }^{99} \mathrm{mcO}_{4}^{-}$) had each compounds can be seen in Figure 2. three peaks, at 1.6; 1.9 and $7.22 \mathrm{~min}$. The The retention time $\left(\mathrm{t}_{\mathrm{r}}\right)$ of ethambutol is at peak at $\mathrm{t}_{\mathrm{r}} 1.6$ and 1.9 min representing the 
Sn-Pyrophosphate, while $t_{r} 7.22$ represent ethambutol. The radiopharmaceutical kit of ethambutol appears in two different detector, UV and GABI-star. The UV detector shown three peaks with the same tr as the cold kit, whereas in the GABI detector there is only one peak appears at $t_{r} 7.5$ represent the ${ }^{99 \mathrm{~m}} \mathrm{Tc}$ ethambutol. $\operatorname{Tr}$ value can be seen in the Table 2.
Since the radiopharmaceutical kits were made in the form of the frozen kit, the stability testing is a parameter that is needed to ensure the kit is in a good quality or not. It was conducted by determining the radiochemical purity and arranged during the labeling process as well as after storage within a certain time period. The test results can be seen in Figure 3.

Table 2. Tr Value of kit in the HPLC

\begin{tabular}{|l|c|c|}
\hline Compounds & $\begin{array}{c}\text { Tr UV } \\
\text { detector } \\
\text { (min) }\end{array}$ & $\begin{array}{c}\text { Tr GABI } \\
\text { detector } \\
\text { (min) }\end{array}$ \\
\hline Ethambutol & 7.78 & - \\
\hline $\mathrm{Sn}$ & 1.69 & \\
Pyrophosphate & 1.90 & - \\
ethambutol & 7.22 & \\
\hline $\mathrm{Na}^{99 \mathrm{~m} T c O} 4$ & & 3.90 \\
\hline & 1.62 & \\
${ }^{99 m}$ Tc-ethambutol & 1.93 & 7.88 \\
& 7.97 & \\
\hline
\end{tabular}

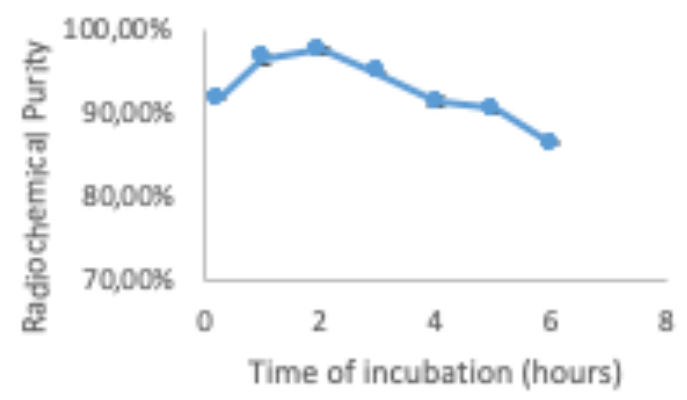

(a)

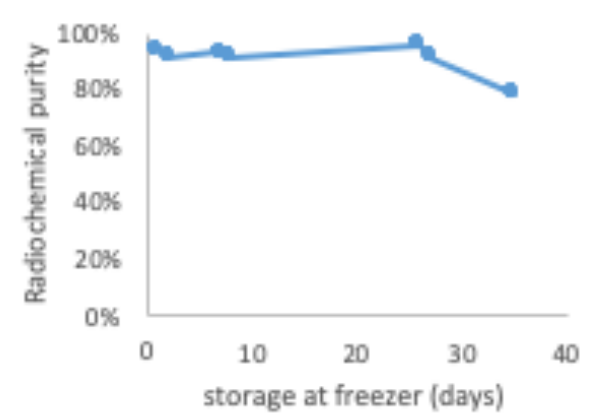

(b)

Figure 3. Percentage of ${ }^{99 \mathrm{~m}} \mathrm{Tc}$-ethambutol radiochemical purity in the time of incubation (a) and in the time of storage (b)

\section{Discussion}

The physical and chemical performance of radiopharmaceutical kit of ethambutol was described at table 1 . The radiochemical purity of ${ }^{99 \mathrm{~m}}$ Tc-ethambutol was $92.61 \pm 4.59 \%$. This result is still met the requirement of a good radiopharmaceuticals. These values also correspond to the results obtained by Nanny K (2007).

The obtained $\mathrm{pH}$ result was different with the study obtained by Nanny et al (2007) due to the different amount of reducing agent. Since the amount of Sn-pyrophosphate was higher, the $\mathrm{pH}$ of the solution increased because the $\mathrm{pH}$ of Sn-pyrophosphate solution was alkaline (9-10). Thus, it is still met the requirement for injected solution of pharmaceutical, which have the values 3-10.5.

Figure 2 shows that all ethambutol have been labeled by ${ }^{99 \mathrm{~m}} \mathrm{Tc}$. It was assigned by there was only one peak that appear in the chromatogram of GABI star detector. The chromatogram also indicates that the labeling process is effective and does not produce any other impurities. A small shift in $\mathrm{t}_{\mathrm{r}}$ value indicates caused by different $\mathrm{pH}{ }^{12}$. The structure is not significantly changed and proves that the reaction takes place through 
the mechanism of exchange labeling where molecules of pyrophosphate replaced by 2 molecules of ethambutol formed the ${ }^{99 \mathrm{~m} T c-}$ ethambutol chelate complex. The structure is shown in Figure 4.

Based on the results obtained in Figure 3 (a), it can be seen that 5 hours after the incubation time, the radiochemical purity of ${ }^{99 \mathrm{~m} T c-e t h a m b u t o l}$ becomes less than $90 \%$. It means that the preparation cannot be used after 5 hours of labeling because the quality is not met the requirement and caused imaging results to be false. The testing also conducted to the radiopharmaceutical kit of ethambutol that stored in the frozen form. The result in figure 3 (b) shown that the radiochemical purity of ${ }^{99 \mathrm{~m}} \mathrm{Tc}$-ethambutol decreased after 27 days of storage.

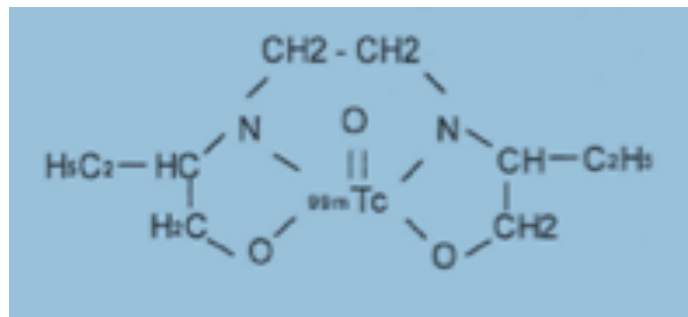

Figure 4. Structure of ${ }^{99 \mathrm{~m} T c-e t h a m b u t o l}{ }^{11}$.

\section{Conclusion}

The radiopharmaceutical kit of ethambutol is performing good physical characteristics and high radiochemical purity of ${ }^{99 \mathrm{~m}} \mathrm{Tc}$-ethambutol both in analysis using paper chromatography, electrophoresis and radio-HPLC. The ${ }^{99 \mathrm{~m}} \mathrm{Tc}$-ethambutol shown the peak at 7.97 minutes using UV and radioactive detector, $\mathrm{C} 18$ column, isocratic system using phosphate buffer $0.2 \mathrm{M} \mathrm{pH}$ 7.4 and Acetonitrile (90:10), flow rate 0.8 $\mathrm{mL} / \mathrm{min}$. The radiochemical purity of ${ }^{99 \mathrm{~m}} \mathrm{Tc}$ ethambutol is $91.44 \pm 0.92 \%$ after 27 days of kit were made. From the results, it was concluded that radio-HPLC analysis provides better information on radiochemical purity as well as chemical purity of the labeling of ${ }^{99 \mathrm{~m}}$ Tc-ethambutol.

\section{References}

1. Bajaj S, Sakhuja N, Singla D, Bajaj Principal S. Stability Testing of Pharmaceutical Products. J Appl Pharm Sci. 2012; 02(2012): 129-138.

2. Mani S, Arunachalam A. Asian Journal of Pharmaceutical Analysis and. Asian $J$ Pharm Anal Med Chem. 2013; 1(December 2013): 184-195.

3. Martins PDA, Silva JL, Ramos MPS, Oliveira IM De, Felgueiras CF, Herrerias R et al. RADIOCHEMICAL STABILITY $\mathrm{OF}$ RADIOPHARMACEUTICAL
PREPARATIONS. In: 2011 International Nuclear Atlantic Conference. Brazil, 2011.

4. Thammana M. A Review on High Performance Liquid Chromatography (HPLC). Res Rev J Pharm Anal RRJPA. 2016; 5(2): 22-28.

5. Todde S, Peitl PK, Elsinga P, Koziorowski J, Ferrari V, Ocak EM et al. Guidance on validation and qualification of processes and operations involving radiopharmaceuticals. EJNMMI Radiopharm Chem. 2017; 2(1): 8.

6. Swartz M. HPLC detectors: A brief review. J Liq Chromatogr Relat Technol. 2010; 33(9-12): 1130-1150.

7. Emert FJVH, Enthe HVL, Chimmel KJMS. Preparation, radiochemical purity control and stability of $99 \mathrm{~m}$ Tc-mertiatide ( Mag-3 ). Ann Nucl Med. 2005; 19(4): 345-349.

8. Mihon M, Tuta CS, Manea C, Ion A-C, Lavric V. Validation of the HPLC method for determination of identity and radiochemical purity of $[18 \mathrm{~F}] \mathrm{NaF} . U P B$ Sci Bull Ser B. 2016; 78(1).

9. Velikyan I. 68Ga-based radiopharmaceuticals: Production and application relationship. Molecules. 2015; 20(7): 12913-12943.

10. Zhou T-Z, Hirth WW, Heineman WiR, Deutsch E. Quantitative HPLC 
Determination of [99mTc]-Pertechnetate in Radiopharmaceuticals and Biological Samples- I . Technique Development. Nucl Med Biol. 1988; 15(5): 493-498.

11. Nanny Kartini, Kustiwa ES. PengembanganSenyawaBertanda99mTcEtambutol untuk diagnosis Tuberkulosis : 2. Karakteristik Fisikokimia Dan Mikrobiologi Ethambutol Tc.Pdf. 2007; : 17-28.

12. S. Letter W. Common Reasons for HPLC Retention Time Drift, Variation or Change. Hillsborough, 2015 doi:10.13140/RG.2.1.5185.3528. 